expected to produce a single new chemical could also produce other new compounds owing to the substrate tolerance of existing enzymes. Second, the introduction into a new organism of a gene encoding an enzyme involved in secondary metabolism could produce more than one product owing to the substrate tolerance of the introduced enzyme.

Third, the introduction of a gene into an organism could disturb secondary metabolite production simply as a consequence of the random gene insertion, with unplanned and unexpected increases in the content of some compounds, owing to changes in the metabolic flux through matrix pathways.

In the Briefing ${ }^{1}$ it was suggested that metabolite profiling or clinical trials might help address the issue of the unknown consequences of manipulating food composition. Both these approaches might be very helpful when assessing the consequences of introducing a single major product, but they would be less productive when assessing the consequences of interfering with secondary metabolism.

Of major concern is the fact that the secondary metabolite profiles of plants can vary considerably, so the effect of introducing a gene into a plant might be predictable only under defined conditions that may not be achievable in the field. The secondary metabolite profile is complex, and extremely small amounts of highly potent compounds can have profound biological consequences - how complete would metabolite profiling have to be?

Richard D. Firn ${ }^{\star}$, Clive G. Jones $\dagger$

${ }^{*}$ Department of Biology, University of York, York YO1 5DD, UK

$\dagger$ Institute of Ecosystem Studies,

Millbrook, New York 12545, USA

1. Butler, D. et al. Nature 398, 651-656 (1999).

2. Jones, C. G. \& Firn, R. D. Phil. Trans. R. Soc. Lond. 333, 273-280 (1991).

3. Firn, R. D. \& Jones, C. G. Rec. Adv. Phytochem. 30, 295-312 (1996).

4. Croteau, R. et al. Plant Phys. 96, 744-752 (1991).

5. Steele, C. L. et al. J. Biol. Chem. 273, 2078-2089 (1998).

\section{Making sense of}

\section{GM tomatoes}

Sir - Your Briefing on genetically modified (GM) crops ${ }^{1}$ refers to Zeneca's GM tomato puree. Hans-Jörg Buhk is reported as saying that "the best performing line was caused by an unpredicted 'sense' event (gene activation). This was a rare event, either a contamination or a chance turnaround [in the genome]". This is wrong.

The phenomenon of sense downregulation by short sense constructs was discovered in earlier research ${ }^{2}$. It has nothing to do with gene activation. Subsequently, for commercial development, genetic modification of a processing cultivar of tomato was carried out with a short sense construct; 210 individual transgenics were produced and these formed the basis for further selection, breeding and development. All the development work has been rigorously reviewed in the United States and United Kingdom by the regulatory bodies. It is wrong to describe the development of this product as being due to "contamination or a chance turnaround". It is misleading to claim this as evidence that GM products are somehow unpredictable.

You show a picture of a can of GM tomato paste with a prominent label. The product was labelled voluntarily in line with our policy of openness, as has been widely reported. Labelling was not a requirement for commercialization. The caption "Backlash: consumer concerns forced action on labelling" is clearly misleading.

Our target was not 'shelf life' as this is a product sold in a can.

Simon Bright, Wolfgang Schuch

Zeneca Plant Science, Jealott's Hill Research Station, Bracknell RG42 6ET, UK

1. Butler, D. Nature 398, 651-656 (1999).

2. Smith et al. Mol. Gen. Genet. 224, 477-481 (1990)

\section{Winners and losers in}

\section{Framework programme}

Sir - We have examined the performance of the countries included in the recently completed fourth Framework programme of research and technology in the European Union (EU). We found that this programme cost about $3 \%$ of total research and development (R\&D) expenditure within the EU, but exceeded $6 \%$ of the national expenditure of countries that devote a small share (less than 1\%) of their gross domestic product (GDP) to R\&D (Greece, Portugal and Spain).

Austria, Italy, France and Germany were net donors of funds, particularly Germany, whose scientists received only $18 \%$ of the funds for their country's 30\% contribution to the budget (Fig. 1). Most other countries were net recipients of funds, with excess funds received by the United Kingdom and Greece representing 30\% and $140 \%$ of their contributions, respectively.

The success rate for grant applications was similar among all countries at $27 \%$ of the proposals filed, except for the remarkable $39 \%$ success rate of UK scientists. Hence the roles of the member states as net donors or recipients of funds largely depended on the involvement of their scientists in the programme. This varied, in per capita terms, 10-fold between Germany, where scientists filed the fewest proposals, and Greece.

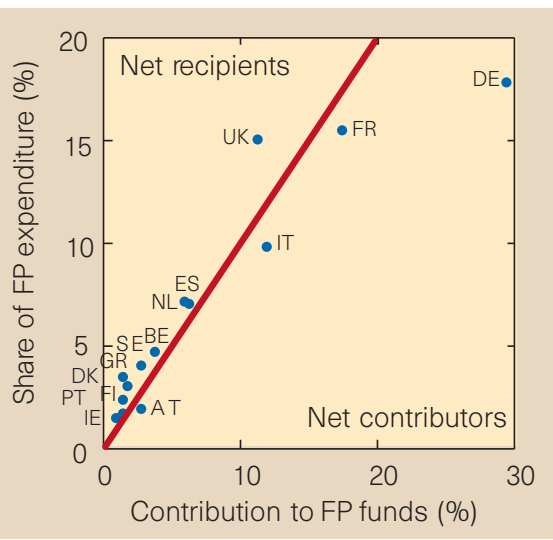

Figure 1 Relationship between contributions and receipts of EU member states participating in the fourth Framework programme (FP). Participants: Austria (AT), Belgium (BE), Germany (DE), Denmark (DK), Spain (ES), Finland (FI), France (FR), Greece (GR), Ireland (IE), Italy (IT), The Netherlands (NL), Portugal (PT), Sweden (SE), and United Kingdom (UK). Data derived from information on funding decisions by the programme's committees. Data are not available for Luxembourg and non-member participants.

Proposals to the Framework programme require the coordination of multinational research groups and the preparation of thorough management plans, which often outweigh the scientific or technical merits of the proposal in the evaluation process. These difficulties deter researchers who can obtain funds from less complex sources. The resources provided by the programme are far more attractive to scientists from countries where $\mathrm{R} \& \mathrm{D}$ resources are scarce (Greece, Portugal and Spain) than to those in countries where $\mathrm{R} \& \mathrm{D}$ investment is comparatively abundant (for example, Germany and France).

The substantial economic benefits the R\&D systems of the EU countries with the lowest per capita GDP obtained from their participation in the programme should be of general benefit to the EU. The development of a stronger R\&D capacity in countries where this sector has been relatively weak should deliver tangible midterm benefits to the entire partnership at a time when countries' economies are linked through a common currency.

The fifth Framework programme (1999-2004) will improve the EU's R\&D capacity further if the application procedure is simplified and the member states allocate more resources to assist scientists, thereby achieving greater participation and overall quality. Carlos M. Duarte ${ }^{\star}$, Maria-José Delgado $\dagger$ ${ }^{*}$ Instituto Mediterráneo de Estudios Avanzados, CSICUniv. Illes Balears, Carretera de Valldemossa km 7.5, 07071 Palma de Mallorca (Islas Baleares), Spain $\dagger$ Subdirección General de Proyectos Científico Técnicos, Ministerio de Educación y Cultura, C/ Rosario Pino, 14-16, 28020 Madrid, Spain 